\title{
Adultery: To be or Not to be?
}

\section{Madhav Raje* \\ Mahakali Polyclinic, India}

*Corresponding author: Madhav Raje, Mahakali Polyclinic, 210, "Kamal Niwas", Nelcos Society, Subhash Nagar, Nagpur, India Pin: 440022, India, Tel: 9822947102; Email: drmadhavraje@gmail.com

\section{Editorial}

Volume 3 Issue 3

Received Date: May 15, 2019

Published Date: May 22, 2019

DOI: $10.23880 /$ mjccs- 16000219

\section{Abstract}

Human society was never fully monogamous. In fact, before civilization polygamy was socially acceptable. However, ascent of civilization brought the rule of monogamy. Monogamy is considered for the growth of institution of marriage. Marriage is a basis of family. Family functions as bonding tie to maintain civilization. Without civilization, human society cannot survive \& evolve further. With this background, argument proceeds to the dilemma of adopting adultery or not. If no, then reasons with benefits are argued scientifically, biologically, psycho-socially. Methods to avoid adultery are discussed. Articles on adultery or infidelity or extramarital sex are published by many, but probably this is a first editorial written by any practicing psychiatrist-cum-psychotherapist. That is why this article becomes relevant to practice by any ordinary individual or by any expert in the field of medical science \& psychology.

Keywords: Adultery; Monogamy; Dilemma; Divorces

Abbreviations: EMS: Extramarital Sex; TA: Transactional Analysis; PAC: Parent-Adult-Child; CNM: Consensual Non Monogamy.

\section{Introduction}

One day a married couple above the age of 50 , priest by occupation, consulted me to ask if they would follow adultery voluntarily? I was stunned! Should one answer this question in professional capacity as a sociology expert or psychotherapist or psychiatrist or even as a clinician or medical doctor? They wanted my answer in my professional capacity. They were to pay me fees. So I was supposed to answer from objective perspective without including subjective or judgmental point of view. Since experts opine objectively their opinions are highly regarded \& may be blindly followed. However, it cannot be denied altogether that my/expert's objective opinion cannot be influenced by my subjective point of view. So now I am answering to both, to inner self \& to my clients as well. My answer must be validated by and in alienation with most of the experts in the world. In the words of Martha Stark my answer should be simultaneously validated by 10000 judges!

With this background I present my stand without being judgmental or subjective. To begin with I ought to review literature and mention it briefly.

Today adultery is a main reason of increased number of divorces. Experts report in more than $90 \%$ of divorce cases adultery is a main reason. Many experts/researchers report, that number of female choosing adulterous behavior have remarkably increased during last decade. As a result male to female ratio of adultery which was not equal earlier has now become almost equal. Broken marriages or choice of remaining single disrupts binding chord of harmony of society. This 


\section{Medical Journal of Clinical Trials \& Case Studies}

change in social equation is a result as well as cause of impaired institute of marriage. Institute of marriage is recognized as a binding tool of society since the beginning of civilization. Hence, broken marriages indicate faltering or potentially weakening texture of society. So logically it appears that adultery potentially weakens the society.

Civilization of past, present \& future inevitably needs social bonding. Society or being social or concern for social issues is a core characteristic of human being. This link extends to theoretical proposition that, 'adultery eventually will destroy social human being' [1]. To be social is one of the basic, innate needs of human being. Other than being social, sex is also a basic innate need of human. Inadvertent focus of any one of these two (social and sex related issues) basic needs can create imbalance in individual and social structure. In fact, being social and basic want of sex fulfilled through marriage could be viewed as two essential components of civilization or social structure [2]. Any civilization remains vibrant and evolves as civilization as long as its components are entwined properly, kept in balance. When norms \& rules are followed by optimum number of people exercising optimum restrains then only civilization can be maintained and kept in balance. Similar views are expressed by Giuseppe Lorini \& Francesco Marrosu of Italy [3].

Institute of marriage serves the purpose of balancing social structure. Increased in divorce cases due to extramarital sex (EMS) inevitably disintegrate social structure. That means, social norms indeed play pivotal role to balance functioning of civilization. Adulterous behavior i.e. non-commitment in marriage breaks this social norm of sexual commitment to each other. If more than $50 \%$ of the population falls prey to EMS then social norms related to marriage obviously gets destroyed, resulting into chaotic, uncivilized situation in the society.

Review of literature reveals that today's life time prevalence of adultery is much more than 50 to $60 \%$ [4]. Some researchers have found it more than 80\%. End result of EMS or adultery not only shatters 'faith' of marital partner but its repercussions touch many major issues of human society. Hence, adulterous behavior or infidelity is by no means a private or single family's or one couple's problem. Adulterous behavior affects us all, present \& future generations. It affects our scientific, spiritual, religious, social, biological wellbeing. And hence all of us are compelled to understand holistic effect of adultery.

\section{Purpose of Marriage}

Why do we need marriages? Sex, companionship, sharing could not be main purposes.

(i) For any ordinary or special person single foremost purpose of marriage cannot be other than procreation. Why do we desperately need to procreate? May be because all of us are sure to die sooner or later, and want to continue our own legacy (to preserve the species), each one of us wants to leave behind our genes. Secondly, procreation is the only virtuous thing any ordinary man or woman can cherish to achieve with relative ease. So as one grows beyond childhood, one of the major purposes of individualized life becomes 'procreation'. This appears like a reward of life to many. EMS can potentially dampen this spirit, may be that is why its condemnation still continues from ages all across the globe. So undoubtedly purpose of marriage is procreation.

(ii) But is there any other purpose of marriage which we are still missing to mention? Does this married life, i.e. married forever, till death, have some special meaning? Why millions of people cherish this marital relationship till death? Do these husbands and wives have some special duty, some special purpose, or certain role to each other? Is their role intimately connected or inseparable from their own individualized purpose of life? Such brain storming leads one to realize that second purpose of marriage is to let partner evolve to the fullest possible potential. Meaning husband cares to facilitate potential virtues, values, perspectives, mental \& physical skills of wife to evolve to become "complete" human \& vice versa. Biologically or scientifically, complete human denotes almost fully evolved, righteously able right \& left hemisphere, which means husband can function with fully evolved right hemisphere like that of his wife's right hemisphere and wife can function with fully evolved left hemisphere like that of her husband's left hemisphere.

Functions of left hemisphere are planning, execution, decision making, work to fulfill ambitions, to do goal oriented activities, etc. Stekler, et al. ascertains role of left hemisphere in outcome based moral judgment [5]. While purpose of right hemisphere is to imagine, exercise sympathy/empathy, perceive emotions of self \& others, to harness artistic skills, etc. Stekler, et al. wrote that right hemisphere itself is sufficient to take intent based moral judgment. Stekler's article adds to our knowledge that right Temporoparietal junction (rTPJ) when facilitated by left Temporoparietal Junction can take complete moral judgment, i.e. intent based \& outcome based moral judgment. Hence, it is proposed that any human/ 


\section{Medical Journal of Clinical Trials \& Case Studies}

individual becomes "complete" when he/she evolves abilities of both hemispheres to the fullest possible use. Similar view is expressed by Giuseppe Lorini \& Francesco Marrosu of Italy in their article published in Frontiers in Sociology [3]. G Lorini \& F Marrosu writes that integration between the two hemispheres plays a crucial role in the full control of moral judgment. Carl Jung too had expressed similarly, where he says man to evolve 'Anima' and female to evolve 'Animus' to become complete \& fully evolved person. This is collective but role oriented responsibility of any marriage partners, Junganian psychology believes.

(iii) In connection to this notion, I believe there emerge third purpose of marriage, which is individualized and self-oriented i.e. every person ought to become fully evolved individual by virtue of married life. Meaning there by husband adapts to inculcate wife's pattern of thinking and feeling and vice versa. Such evolution is possible when one remains in marriage for lifetime. Life time association is required to (i) understand/comprehend and exchange male/female virtues and (ii) to de-learn subjective perspective of pleasure seeking activities or basic/animal instincts, to adapt to re-learn to evolve fully. Similar views are expressed by Mathew Henry in 2006.

In other words, Evolution also means integrating demon into deity within. Integrating demon does not mean dissolving demon into deity. Integrating demon means, identifying demon within, accepting it, taming it and using demon's energy for the good of self \& others. This evolution can be attained through faithful spousal relationship. There is evidence in history that solo individual can also attain such stage of evolution, but for any ordinary individual it is easier through spousal relationship.

Other than evolution of self, long cherished married life also provides companionship and caring/nursing partner for old age. Lifelong marital relationship, subtle in some cases \& certain in some cases provides psychosocially and morally bonded caretaker. Utility of this long life relationship cannot be undermined if organ transplant (e.g. kidney donation) is needed for son/daughter. Purpose of life: While exercising such virtuous \& faithful role play in married life it is easy for one to realize and serve the purpose of life as well. Search in literature of western \& eastern philosophy revealed that there are three purposes of life, (a) (Moksha) permanent release from this cycle of birth- rebirth or enlightenment, (b) happiness and (c) pleasure. Most of the researchers, philosophers including me think that purpose of life are "to gain happiness \& to spread happiness". To rise to this stage of human life of only to gain \& spread happiness, beyond the stage of adhering to pleasure seeking life activities, one ought to 'evolve'.

So this discussion leads to the notion that committed, faithful marriage may serve the fulfillment of purpose of human life. Marriage offers opportunity to 'gain \& spread happiness'. Because happiness not only comes from within but invariably from between! So happiness comes from in between married partners. Similar views are mentioned by Jonathan Haidt in his famous book 'The happiness Hypothesis' [6]. But tyranny of life and that of marriage is that few acknowledge this view. Most of us live for pleasure almost every moment. Nothing is bad in it. Pleasure seeking activities are okay. But does this pleasure seeking activity lead to happiness, is a million dollar question. Unless pleasure transforms into happiness, pleasure cannot last long. After all; pleasure is always a situational, individualized, time limited early phase of happiness. Pleasure is always a conditional and subjective feeling. It does not transcend from one to another. But, when pleasure transforms into happiness, it not only transcends from one individual to another but lives long in subtle form in the minds of many individuals. For example, when two individuals enjoys extra marital sex (EMS) then pleasure experienced by both is individual, situational and time bound. Such pleasure cannot be transcended to others. Neither such pleasure can be perceived as happiness, since EMS is condemned by one and all since the beginning of civilization.

But, if these two individuals enjoy sex within marital ties which is acceptable to next of kin \& society then such a sexual pleasure is easily transcended into happiness. This happiness is shared by all. For example, procreation resulted out of this marital sex, i.e. child birth offers happiness to one and all. Time line of pleasure lengthens and expands! Instead of awakening for \& developing inner vision people at large became crazy to seek pleasure. Society considers physical activity as a foremost activity of enjoyment; hence most of us get involved into such activities, e.g. devouring food, sex, sight-seeing, luxury, etc. This is a shift in the perspective of an individual \& society as well. This shift has engulfed all of us enormously to such an extent that values of life, inner peace and evolution of self-have taken a back step. Evolution of humans has occurred from un-civilized to civilized form to modern form of humans. But we have not progressed ahead of modern form. So time has come to re-meditate on evolution of one \& all. Ultra-modern human ought to 


\section{Medical Journal of Clinical Trials \& Case Studies}

be evolved one; evolution has to be an inner one! Inner evolution indicates evolution of mind/psyche/inner self. Carl Jung once had said those who look out; dream, and those who look within; see. So time has come now to remeditate if we should engage in adulterous behavior or not. To be or not to, is a like a huge shark, ready to swallow. Unless our inner self \& outer image merge, it is difficult to overcome this potential calamity.

How to avoid EMS? - To refrain from EMS does not necessarily mean de-meaning pursuit of pleasure. Pleasure is integral part of human life. Eric Berne says in his theory of transactional analysis (TA) while explaining theory of Parent-adult-child (PAC) that when any one is involved in seeking pleasure then it is assessed that person is playing a role of child. If pleasure seeking activities are predominant \& consistent then such a person is recognized as a person who plays 'dominant child role' most of their lives.

Explaining further he writes about the roles we play, i.e. Parent-adult-child (PAC) every day alternatively or simultaneously. PAC does not designate biological or chronological stages of life, meaning child does not mean age of a person or parent does not mean real biological parent. A single person may play all these roles at one time or alternatively. Child role designate activities based on wish, desire, pleasure, fun, enjoyment, etc. So I perceive that EMS is an activity of child role. Anyone's whose 'parent role' (as per TA) is not strong enough may play dominant 'child' role even if person is 30 years old, because according to TA 'parent role' dictates control or restrictions or what not to do and what to do.

Attributes of 'weak parent role' may be deep rooted in childhood experiences of parenting style of real parents. Most of time liberal or neutral style of parenting fails to teach discipline. Guidelines of behavior in adult life are not carved out meticulously directly or indirectly by biological parents during childhood. As a result of liberal attitude or absence of democratic discussions within the family initiated by elderly family members and significant others, a child or adolescent or growing adult can fail to exercise moral restrains when opportunity strikes. So many adults even after 50 years feel uncertain about to be or not to be adulterous! Couples who adapt to this pattern of sexuality/infidelity are also called followers of consensual non monogamy (CNM). Some researchers believe that it is part of an ambivalent sexual attitude, reasons for which can be discussed below.
Solution to deal with such situation is to make one's own 'parent role' strong. One's own weak parent role can be transformed into strong parent role simply by asking oneself to do so. So awareness is the key! Secondly; take inspiration from a person whose parent role is strong. One can take inspiration from real life leaders, or disciplinarians whose parent role is strong. But even if strong parent role does not help in some cases, then probably attachment theory or attitude of that person can offer explanation. Why do some own permissive or ambivalent sexual attitude? EMS is an expression of attitude or personality or way of thinking. Ambivalent or permissive sexual attitude may be explained by attachment theory. Disordered attachment in childhood causes persistent anxiety which pervades into adult life. Such anxiety attributes ambivalent \& avoidant attachment attitude. It is observed by many that both these types of attachments do play significant role in adultery [6].

Ambivalent attachment is also recognized as attachment anxiety. Individuals with attachment anxiety are anxious, uncertain, if they would get sexual pleasure from their married partner or not. This is psychological or mental or virtual uncertainty, so it is present even before marriage. Such individuals rationalize with themselves that marital satisfaction is anybody's basic want, which must be fulfilled anyhow. If incidentally married life becomes unsatisfactory then as result of anxiety, they convince themselves that EMS can be an easy resort. This rationalization or intellectualization, explained in Sigmund Freud's unhealthy defense mechanism remains the basis of EMS of many naïve or otherwise would be faithful husbands/wives. Sublimation, healthy defense mechanism, could be a solution to such misery. Handling of such issues falls under the domain of experts in psychosocial-biologically trained personnel. Hence I propose that psychological intervention from experts or relevant awareness programs run by experts is a need of time to prevent EMS. Psychiatrist or medical doctors ought to come forward to raise alarm \& spread awareness program for monogamy.

\section{References}

1. Laura Perrins (2018) Adultery is fine - for the little people. The conservative woman.

2. K U Sulaiman, Civilization: History, description, common characteristics, \& importance.

3. Lorini G and Marrosu F (2018) How individual habits fit/unfit social norms: From the Historical 


\section{Medical Journal of Clinical Trials \& Case Studies}

Perspective to a Neurobiological Repositioning of an Unresolved Problem. Front. Sociol 3: 14.

4. Nicolle MZ (2017) Decision Science, Risk Perception \& Infidelity. SAGE Open 7(1).

5. Dewall CN, Lambert NM, Slotter EB, Pond RS, Deckman T, et al. (2011) So far away from one's partner, yet so close to romantic alternatives: avoidant attachment, interest in alternatives, and infidelity. J Pers Soc Psychol 101(6): 1302-1316.

6. Jonathan $H$ (2006) The happiness Hypothesis: Finding modern truth in ancient wisdom. Basic Books. 